\title{
Working and Learning in a Field Excursion
}

Torstein Nielsen Hole*

bioCEED-Centre of Excellence in Biology Education, Department of Biology, University of Bergen, 5006 Bergen, Norway

\begin{abstract}
This study aimed to discern sociocultural processes through which students learn in field excursions. To achieve this aim, short-term ethnographic techniques were employed to examine how undergraduate students work and enact knowledge (or knowing) during a specific field excursion in biology. The students participated in a working practice that employed research methods and came to engage with various biological phenomena over the course of their work. A three-level analysis of the students' experiences focused on three processes that emerged: participatory appropriation, guided participation, and apprenticeship. These processes derive from advances in practice-oriented theories of knowing. Through their work in the field, the students were able to enact science autonomously; they engaged with peers and teachers in specific ways and developed new understandings about research and epistemology founded on their experiences in the field. Further discussion about the use of "practice" and "work" as analytical concepts in science education is also included.
\end{abstract}

\section{INTRODUCTION}

In several empirical disciplines, students, teachers, and researchers travel out into the field to engage with real-life phenomena, gather data, and otherwise enact science. Field excursions are often lauded as crucial learning experiences by students and teachers, despite the relatively high costs of this pedagogical approach (Boyle et al., 2007; Goulder et al., 2013; Harland et al., 2006). In the past few decades, a large body of literature has accumulated that examines individuals' emergent knowing as they engage with working practices. In conjunction with this, several theoretical contributions have argued for an increasingly advanced distinction of knowledge dimensions, which lends credence to pedagogies that afford students (and others) with access to learning by working in varied circumstances (Duguid, 2005; Fuller et al., 2005; Kennedy et al., 2015; Nicolini, 2012; Polanyi, 1966). However, such perspectives have not yet been applied to investigate field excursions in tertiary-level biology training or similar empirical disciplines, despite the fact that field excursions resemble work, with an emphasis on enacting knowledge and laboring together to create knowledge (Billett, 2004). The emphasis on work is important to note in contrast to advances in understandings of museum or science center learning. Here, context and personal dimensions are emphasized as important analytical contributions (Rennie and Johnston, 2004), though there is less emphasis on the students' enactments of science practices to understand their learning. In addition, adults act with greater agency and can contribute substantially to knowledge production in their activities, which increases the need for a specific examination into tertiary education.

In work, individuals move out into workplaces, which consist of practices nested within a culture, dependent on the specific circumstances in every given organization (Gherardi, 2009). Similarly, one of the main characteristics of field-based learning is the actual movement of students into new contexts. It is therefore appropriate to consider a "situated" (or sociocultural) conception of knowledge and learning. This term is perhaps best known in Lave and Wenger's (1991) work; they discern learning in terms of individuals' "situatedness" in working communities. These are working
Hannah Sevian, Monitoring Editor Submitted August 23, 2017; Revised December 26, 2017; Accepted January 9, 2018

CBE Life Sci Educ June 1, 2018 17:ar24 DOI:10.1187/cbe.17-08-0185

*Address correspondence to: Torstein Nielsen Hole (torstein.hole@uib.no)

(c) 2018 T. N. Hole. CBE-Life Sciences Education (c) 2018 The American Society for Cell Biology. This article is distributed by The American Society for Cell Biology under license from the author(s). It is available to the public under an Attribution-Noncommercial-Share Alike 3.0 Unported Creative Commons License (http:// creativecommons.org/licenses/by-nc-sa/3.0)

"ASCB ${ }^{\circledR "}$ and "The American Society for Cell Biology ${ }^{\circledR "}$ are registered trademarks of The American Society for Cell Biology. 
communities into which individuals gradually integrate by employing tools, vernacular, and other practices inherent in the community in which they are participating.

King and Ginns (2015) have shown how situated knowing is a crucial affordance in middle school students' field excursion experiences. The authors found that students' application of context helps them to engage with scientific concepts and aid teachers in their pacing and facilitation of a more scientifically driven pedagogy (e.g., to question, discover, and otherwise engage with real-life phenomena). Roth's (2005) work on scientists' classifications displays how scientists develop their working knowledge through situated procedural tasks. These procedures are in reality important decisions with scientific ramifications. One example is species taxonomy, in which scientists work as best they can to advance transparent and wellfounded knowledge through working with available materials, even though the researchers' situatedness and personal knowledge (i.e., the scientists' life history and other surrounding circumstances that are hard to convey in text) certainly affect, or even steer, this work (Polanyi, 1962).

The theoretical contributions noted above do not clearly define the pedagogical value of field excursions in higher education, though the sociocultural conceptions of learning suggest that field excursions' situated and material affordance can manifest itself as tacit knowing, which means that important learning is not easily discernible through verbal means (Strati, 2003). The students work with science in field circumstances, they enact scientific culture, and develop situated capabilities. Thus, mind and context work as a unit, or as described by Wertsch (1991): "The sociocultural approach to mind begins with the assumption that action is mediated and that it cannot be separated from the milieu in which it is carried out" (p. 18).

The present paper is a contribution to the field of biology education research and specifically a response to calls for increased knowledge about the role of field-based pedagogies in biology education (Singer et al., 2013). It uses sociocultural learning theory as a lens to examine particular aspects of students' learning during a specific field excursion. Practice-oriented theories of knowledge and knowing emphasize the legitimacy of work in individuals' learning. In the current investigation, these conceptions are employed to investigate students' work performed in relation to science education. Although the investigation is centered on biology education, the findings and methodology can be useful to consider in other disciplines that employ field excursions in their training.

The research question that the investigation aims to address is: How does the students' engagement with fieldwork practices influence their development of biological knowing? The use of the term "knowing" when referring to the students' development of knowledge, new conceptions, and fresh ways of thinking (i.e., learning) indicates a focus on the emergence of the students' tacit, situated, and conceptual capacities. These capacities consist of understanding how to make use of scientific tools, knowing, and practices (i.e., knowing how to enact them) and expanding knowing of concepts and propositional knowledge (i.e., knowing that; Duguid, 2005). The phrase "engagement with fieldwork practices" connotes the sociocultural activity through which the students come into contact with, work, and enact scientific knowledge (i.e., biology).
The present work builds on ethnographies of work and learning (e.g., Lave, 1988; Lave and Wenger, 1991) and scientific culture (Latour, 1987; Knorr Cetina, 1999; Roth and Bowen, 1999). These works have documented various practices (of knowing) among scientists in laboratories and otherwise in their everyday life, but they have not focused on students' situated learning in fieldwork especially and sociocultural learning theory in general. Lave (1996) has highlighted how learning emerges as individuals access new experiences, that is, engage with practices. Practices pertain to patterns in individuals' behavior; they are often routine and ingrained in culture. Culture pertains to symbols, artifacts, and institutions, whereas practices refers to the enactment, the activity, which constitutes work and learning. In this case, the practice of enacting of science (using knowledge, phenomena, and methods prevalent in biology) in a field excursion. It is important to distinguish between individuals' engagement with practice, the culture in which they are a part of, and the community by which practices are enacted. Often, empirical data are mostly concerned with practices, because they are more easily discerned, and from these data, broader understandings are inferred. In this conception, culture and knowledge are constituted by the practices of its members (Gherardi, 2012).

Short-term ethnographic techniques were employed to investigate fieldwork as a cultural practice (Pink and Morgan, 2013). Ethnographic methods excel in uncovering and documenting routines, practices, and other patterns of human behavior - in this case, students' activity in a specific, limited circumstance. The present investigation was performed through direct participation; the author was embedded in a 9-day high-intensity field excursion to gather observations. These observations were later structured and further developed in interviews to enable a triangular approach to develop the observation findings.

\section{CONTEXT}

The field excursion took place over 9 days during early autumn on Svalbard, a sparsely populated archipelago in the high Arctic where permanent habitation is sustained by the mining industry and a university center. Given the ease with which researchers can access high Arctic conditions, and Svalbard's location between the permanent ice sheet and receding ice, the archipelago is subject to high research activity in diverse scientific disciplines (for an overview, see the Svalbard Science Forum, n.d.).

\section{The Students, Teachers, and Ship}

The excursion included both marine and terrestrial biology content. Lodging was provided on a ship, which was moored along the coast to enable sampling, outdoor lectures, and observations at different sites. The ship typically sailed during the night to new sites. All students had shared cabins and access to common rooms, the bridge, and a mess deck.

Fifteen students from Europe and North America, aged 20 to 25 , all of whom consented to be part of this study, participated in the field excursion. All teaching (and therefore, all collected material) was conducted in English; most students had a different native tongue but were proficient in English (i.e., all could carry out a discussion on the subject matter). The field trip was part of a bachelor's-level, single-semester, course. The students had completed at least two semesters of tertiary-level natural 
science education before enrollment, one semester of which had to consist of biology subjects. The field trip occurred at the beginning of the course, with 1 week of course work before the trip. The students had not encountered one another before the course.

Three experienced tertiary-level biology teachers led the field trip. These teachers have conducted research and taught extensively in the area previously. Binoculars were freely available and much used, allowing the students to investigate birds, cetaceans, and the topography during their free time on ship. Both students and teachers often used the bridge and the open deck to make these observations. They were able to ask the captain and first mate questions about the ship and the local area. In the evenings, the students planned future sampling activities, handled collected samples, and digitized data.

\section{Activities during the Field Trip}

The field trip was a component of a larger course, of which the articulated learning outcomes included the ability to undertake sampling, the ability to understand key characteristics of the Arctic flora and fauna, and the planning and conducting of a research project based on data collected during the field excursion. The teachers expressed an expectation that the field trip would make an important contribution toward developing these capabilities.

The students were divided into four groups, and each group's project comprised research methodology and dissemination. Each project had specific aims that were developed by its student group. The aims involved data gathering, such as mapping the occurrence of species and environmental variables in various habitats, for example, soil composition, humidity, temperature, and vegetation prevalence. During the trip, the students collected samples and other data for subsequent laboratory analyses on campus. The projects were completed and assessed by dissemination through oral presentations and reports; an accepted report (graded as pass/fail) was required for the students to be admitted to a graded course exam.

Each group's research goals and collection methods were organized and planned by the students, although the teachers authorized major decisions, such as where the ship was to be moored each day, and gave input on relevant sites for sampling. Hence, the students autonomously planned much of the field activity on land and instigated several field activities, most of which were discussed with teachers and fellow students.

The teachers planned visits to sites that were deemed interesting in a biological, cultural, and historical sense. These included visits to bird cliffs, glacial moraines, and other sites to investigate associated fauna and flora. Overall, the teachers' principal concern was the successful planning and completion of the students' research projects, which would also contribute to the students' knowing about and handling of Arctic flora and fauna (i.e., research and field skills). The teachers frequently talked to the students about occurring phenomena as the class moved from one area to another throughout the field trip; the close proximity between students and teachers on the ship afforded many opportunities for such encounters.

\section{METHODS}

The data were collected through semiparticipatory observation during the field excursion and through two group interviews that were conducted 2 days after the excursion. Thus, the investigation employed a triangulation procedure wherein the interviews validated the observations. Every evening during the field excursion, the notes from the day in the field were compiled into a document containing information about observations and subsections with reflections about what the observed activities signified in terms of expressions of knowledge-building practices. Notes were gathered during the onshore components of the course and audio recordings were gathered once the students were stationary for long periods of time, for instance when working with sampling plots. Photographs were also taken throughout. For instance, the students' particular work with gathering samples using frames was examined through 1) direct observation of the students' actions; 2) listening to their conversations; 3) photographing their actions; 4) asking the students to narrate their handling of the material as it occurred; 5) asking the students about their work directly subsequent to it; 6) asking the teachers about the students' work; and 7) interviewing the students about their experience subsequent to the field excursion.

The interviews comprised two semistructured group interviews with seven students in each session; each session lasted approximately 1 hour. One student was unable to join the interview. The interviews were audio-recorded and later transcribed. The aim of the group interviews was to facilitate students' comments on the observed activities in the field. The interview guide was created through consultation with subject teachers to ascertain that the themes would make sense to the students as intended. The teachers also deemed that the students would be at ease with discussing their individual conceptions about their activities in the field, even in cases in which their conceptions were contradictory. The same interview guide was used for both groups. The interview was structured to facilitate general discussions about field-based learning and about concrete experiences in the field and therefore functioned as a validation and expansion of observational findings (Creswell and Miller, 2000). The interview data were transcribed verbatim. Names are pseudonyms in all excerpts. Sounds without distinguishable meaning are not included in the excerpts to make the reading clearer (recommended by Silverman, 2013).

It is worth noting that the interview process presumably had an effect on the students' attainment of learning from the course. In essence, the act of interviewing the students might trigger reflective learning processes, thus the research method approaches what Angrosino (2005) holds to be interactive; the research method has an impact on the participants. The students were informed at the outset of the study that no information would have an impact on their grades or course assessments.

\section{Analysis}

Both observations and interviews discerned working practices in which the students participated. Practices that the students indicated were of particular interest or that seemed to be decisive learning experiences for the students (e.g., occurrences of students talking about the novelty of the experience or instances the students themselves highlighted to be important learning) were developed further with thick descriptions. For instance, recordings of student utterances and context documentation were employed to make better sense of the material (Watson, 2012). The analytic focus was to identify knowing as it emerged 
TABLE 1. Example excerpt of data compilation and analysis ${ }^{a}$

\begin{tabular}{|c|c|c|}
\hline Time and observation & Interview questions & Analysis (description of practices) \\
\hline $\begin{array}{l}\text { 13:48: Difficulty in finding a new area. Some discussion. } \\
\text { Observation/recording of plant group led by Stein (Jen, } \\
\text { Alice, Karin, and Grant) } \\
\text { Group members display gaps in measuring temperature } \\
\text { and identifying feces } \\
\text { 13:51: Discussion. What sort of feces are these? } \\
\quad \text { Discussion about whether they are from a fox or a } \\
\text { ptarmigan. }\end{array}$ & $\begin{array}{l}\text { Have you worked with sampling in } \\
\text { this way before? } \\
\text { Was this different in any way from } \\
\text { previous experiences? } \\
\text { What did you think of your sampling } \\
\text { as a method? }\end{array}$ & $\begin{array}{l}\text { John talks about how they determined } \\
\text { different items in the frame through } \\
\text { discussion. They would compare their } \\
\text { findings and discuss how they came to one } \\
\text { estimate of cover as opposed to another } \\
\text { and then make a decision based on a } \\
\text { common understanding of the subject } \\
\text { matter. }\end{array}$ \\
\hline
\end{tabular}

${ }^{a}$ The example shows how observations consisting of note taking and other materials translated into interview questions. The resulting transcript was then analyzed descriptively, as shown in the "Analysis" column.

through students' engagement with and enactment of fieldbased practices, that is, their sociocultural learning activities. This was further founded on Polanyi's (1962) notion that individuals' situated engagement with practices is a decisive component to discern (personal) knowing. The data were categorized by division into meaningful subparts of instances that examined scientific activities as they were observed and the students' comments on these instances (Silverman, 2011).

The initial ordering of subparts commenced at the very outset. As in other investigations using ethnographic methods, the act of observing and reflecting over the course of the data gathering is a crucial part of the analysis (Hammersley and Atkinson, 2007). Several instances were striking as being particular, useful, and salient experiences that pertained to the students' learning trajectories. As recommended when employing shortterm ethnographic techniques (Pink and Morgan, 2013), findings were continuously discussed with peers and preliminarily analyzed with theoretical framing on-site; I shared thoughts on the material with the on-site teachers and external researchers to get feedback on the initial findings and the general theoretical framing. High-intensity implementation of theoretical perspectives is recommended when there is limited time available to gather data (Pink and Morgan, 2013). Initial findings highlighted, first, that salient knowing-in-practice consisted of students' participatory processes, particularly those connected to group work during sampling (e.g., how to enact research procedures in the face of unforeseen events); and second, that there was value in the direct observation and tactile interaction with several basic, though foundational, biological phenomena (e.g., the smell of walrus permeating the beach and observing death when predator meets its prey). To advance these findings, probing questions (e.g., "Tell me more about the collaboration with your peers when working with sampling"; "Tell me about your thoughts concerning the observation of the skua that attacked the ptarmigan") were posed to the students in the group interviews.

Initially, it was clear that sociocultural processes were facilitated by students' engagement with phenomena, their participatory, group processes, and their cultural integration into the role of a biological scientist, all of which is well understood in sociocultural theory. They also engaged with materiality through personal engagement with phenomena (e.g., by observing, touching, and otherwise deriving biological knowledge from field materials). The initial analysis made use of descriptions of the materials. The first analysis is exemplified in
Table 1. After the first analysis, it became apparent that, in order to account for the activities of individuals as they come to engage in participation in groups and in communities, it is necessary to adopt a comprehensive understanding about learning in these instances. Rogoff's (1995) three-pronged analysis of sociocultural learning shows how analysis can treat different circumstances in different units. She dubs these layers "participatory appropriation," "guided participation," and "apprenticeship." These are concepts that have profound cognitive and cultural ramifications, as Rogoff holds that the three concepts cannot be understood separately, though they can work as analytic units. Rogoff's model is an underappreciated iteration that attempts to account for sociocultural learning and includes analysis of individuals' knowing. Therefore, this analysis responds to a pervasive critique of sociocultural learning theory: that it fails to consider individuals' subjectivity, dispositions, and will to participate in practices (e.g., Billett, 2007; Mason, 2007; Sfard, 1998).

The entire body of material, consisting of both interviews, observation notes, photographs, and audio recorded in the field, was analyzed by employing Rogoff's (1995) overview of sociocultural learning. This analysis was performed with Nvivo; the software was employed to organize and give an overview of the material. Different iterations of data (e.g., interviews and observations) could pertain to the same theoretical dimension.

\section{Findings}

The students' sociocultural activities are discerned according to Rogoff's (1995) three dimensions of learning. This division is analytical, though all aspects co-occur in different activities, as continuously emphasized in Rogoff's discussion of the three dimensions. For instance, students working in plots enact apprenticeship, guided participation, and participatory appropriation processes, as will be presented in the following sections.

\section{Biologists Discussing Rocks: Guided Participation}

Guided participation is held by Rogoff to be an "interpersonal process in which people manage their own and others' roles, and structure situations (whether by facilitating or limiting access) in which they observe and participate in cultural activities" (1995, p. 147). Participation is often the hallmark term of sociocultural theory, and learning is discerned by examining the procedures students use when participating in an activity (e.g., Roth and Lee, 2004). 
Students' participation in enacting a specific aim (i.e., conducting their research projects) was a prevalent iteration of the students' practices. Specifically, this dimension emerged in how disparity in the students' understanding resulted (seemingly) in lower-quality data and unclear characteristics of samples. The students therefore identified the need for a cohesive understanding of the subject matter (i.e., sample collection) that was discussed and developed collectively. Further, the students reached this cohesive understanding through communication about conceptions in the group. This interaction, wherein the students sought other students' opinion about gathering samples, was observed frequently during the field course. Students read up on methods and then frequently took the role of experts in their particular data-gathering sessions.

The ship arrived at a new location every morning. Here, the students and teachers were set ashore and walked inland to predetermined sites considered suitable for the sampling of plants, soil, and vertebrates. The student group whose samples were to be collected organized the rest of the students into groups and marked sampling sites with wooden frames. Each framed plot involved investigation of plants, soil, fungi, and other environmental factors. The prevalence of species was used to assess the context of a specific site (e.g., humidity, soil temperature, and light availability). The determination of samples in the field sparked several discussions about what actually constituted "soil" or on the prevalence of a species and so on. The group members often found that their subjective assessments varied wildly. One student might identify soil to cover $70 \%$ of the frame, while another might identify $70 \%$ to be sand. Students also discussed plant identification and how the wooden frames should be placed to give an accurate description of the area (e.g., "snow-bed slopes" and "flat land"). Again, students found that no incontrovertible solution could be found, leaving the students to make decisions as best they could on-site.

The preceding descriptive summary is based on observations of the students' work during the field cruise. The students created the necessary data sheets on campus before going into the field to perform data sampling. This caused a disparity between the design and its implementation in the field. Students quickly realized that certain indicators, for example, percentage of moss in the plots, were exceedingly difficult (i.e., time-consuming) to measure and thus affected the number of plots that could be investigated. Time and efficiency were thus found to play an important role in data collection, and more so in Arctic conditions, where weather and safety remain an issue. Further, species identification emerged as a skill that requires specific training to assess plots precisely, and the students instructed one another on helpful characteristics to advance the process. They found that the ability to accurately describe a plant on campus does not guarantee taxonomic ability in the field, where plants are frequently immature or damaged.

The collaborative activities in the field demonstrated how the students discuss different aspects of data sampling in groups (see Figure 1). Throughout the sampling of soil crust, the students displayed an ambiguous perception about the characteristics of gravel, soil, dirt, and sand. The students, after identifying this ambiguity, found that they needed to reach a common understanding to enable efficient and systematic samples. One student explained this collaborative process as follows.

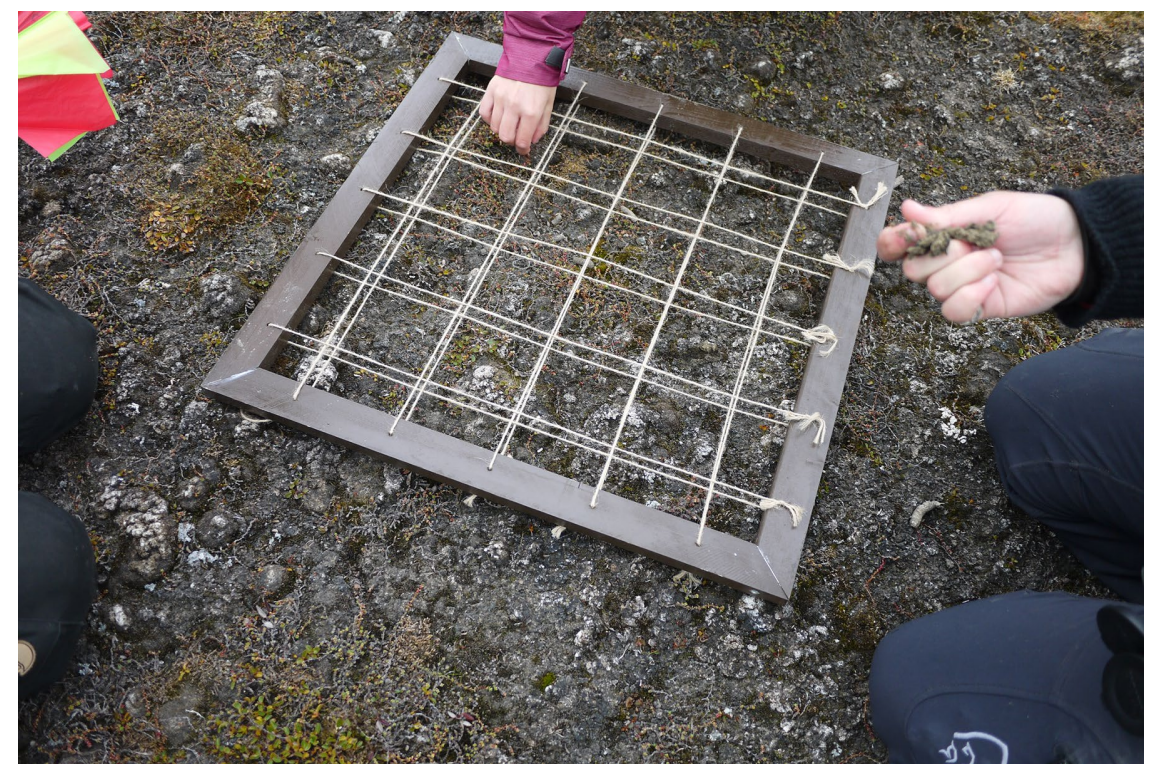

FIGURE 1. Students worked extensively with frames to map the environment. This task proved more challenging than the students had envisioned before the field excursion. The illustration shows students mapping percentage coverage of willow (Salix), saxifraga, mosses, and lichen. The students developed procedures to determine coverage using what they found to be acceptable error margins. The students' efforts were also hampered by the relatively small size of high Arctic flora, which made several plants difficult to detect.
Grant: Yeah, and also that you make an agreement that you, if there is something that there is a disagreement about what is soil, what is stone cause we had a place with a lot of like gravel, small stones. And then it was like, just felt like just most important thing that every group did the same. Then they just went around and "okay when the stone is smaller than this one, it is soil" so as [we] had like agreement.

These are guided participation efforts, wherein individuals work together toward a joint goal, whether tacit or explicit (Billett, 2004). In this case, it served to develop the general learning outcomes of the course (e.g., to develop research capabilities) and the students' dispositions toward participating in resolving a scientific problem. The students developed their procedures continuously; in one instance, students employed an average of the different students' assessments: one student would surmise a frame to consist of $30 \%$ gravel, while another surmised $70 \%$, giving an average of $50 \%$. While no fully satisfactory method was established, 
the students continuously attempted to increase the precision of their assessments and identified problems with their procedures. For example, the large disparity between 30 and $70 \%$ might indicate that they used drastically different procedures to observe the gravel itself.

\section{Epistemology and Death: Participatory Appropriation}

The second of Rogoff's (1995) analytical concepts, individuals' participatory appropriation, is concerned with the following: "through participation, people change and in the process become prepared to engage in subsequent similar activities. By engaging in an activity, participating in its meaning, people necessarily make ongoing contributions" (p. 150). Individuals can participate in activity, though they can also choose to disassociate (Hodges, 1998). This is a negotiation in which individuals discern their own stance toward participation. In this case, participatory appropriation applies to both how biology practices accommodate students' dispositions and understandings and whether biology is a valuable pursuit for students, both to create new knowledge (i.e., epistemologically) and as a personal trajectory (e.g., a pursuit of value for their education).

In the interviews, the students were asked to detail diverse learning experiences concerning both field skills and phenomena they encountered (see Figure 2), such as glaciers and how the surrounding geography and biota can be shaped by glacial influence. The students frequently referred to learning experiences as "a process of remembering." The students seemed to employ the term interchangeably with "learning." Others have shown how researchers are better served by not accepting terms used in interviews at face value, but rather by evaluating the contents of interviewees' utterances (Marton and Säljö, 2005). Specifically, different settings were of varying quality in terms of enabling the students' remembering. The students explained this in the following ways:
I: Can you tell me more about what helps you "remember"?

Rob: Well, just that you are seeing it for yourself and you don't really know what it is, but you are trying to explain it by using things to learn [...]

I: What about the senses?

Kim: I think it was the...

Rob: Yeah, yeah, like the shore.

Kim: Yeah, exactly.

Rob: And you could smell it.

Kim: It gives you much better memory if you have, if you have seen it, and you have that visual memory in your mind rather than just trying to remember words.

In this instance, one student iterated how the "visual" aspect of field-based education makes remembering concepts easier. This conception associates learning with sensory experience and variety in sensory experience with aiding development and learning; this certainly alludes to the difference between observing an illustration and observing phenomena in real time, due to the level of abstraction. Further, the students highlighted the visual sensory aspect, because learning is perceived by the students to be dominated by the memorization of facts and concepts during lectures and other campus-based education practices. The students emphasized the difference in learning in the field excursion, especially the ability to observe phenomena as they occur:

Mira: Yeah, you can sit inside and learn all the theory though it is truth and that is what is happening outside. I think that for me personally it is, you are learning it in a totally different way when you are out, and I just think it's a lot more easy to get "in" and to remember when you are out there where it is actually happening, and you can see it and relate to what you see and learn.

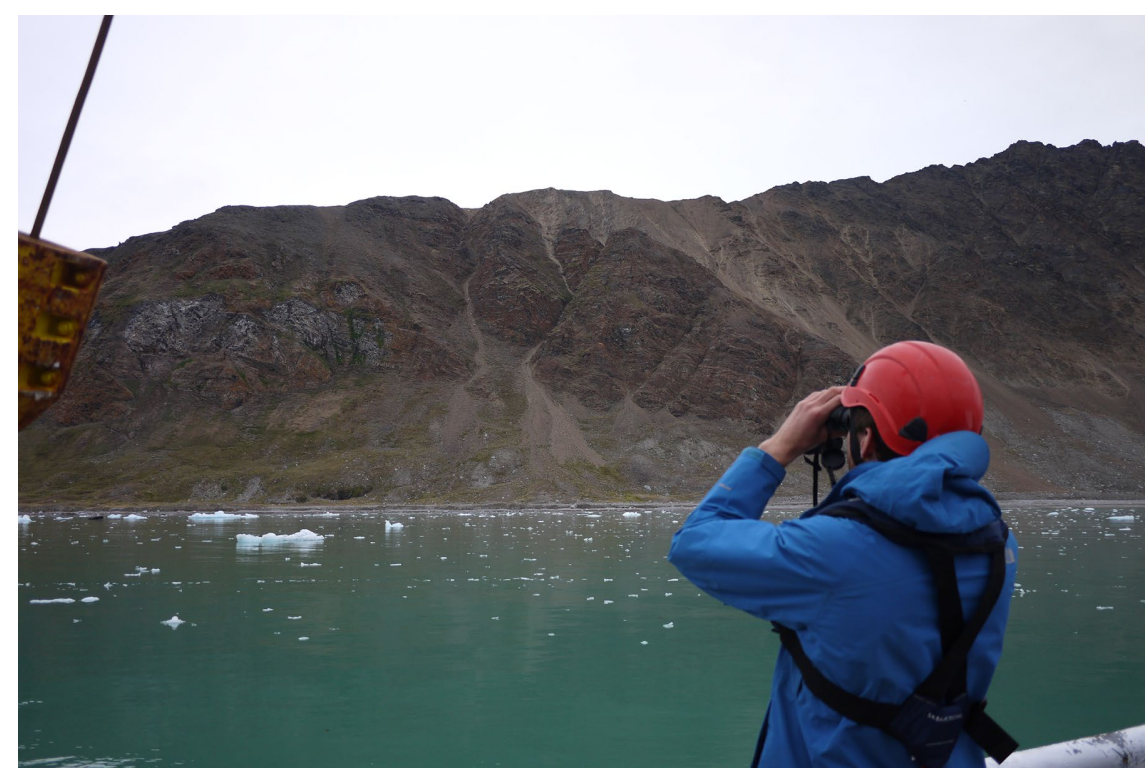

FIGURE 2. Observation of bird cliffs was made possible with access by ship. The green coverage below the cliffs to the left marked the presence of birds (i.e., there is guano that encourages plants). This was a striking contrast, as nearly all landscape observed from the ship was brown, black, or gray.
The above iteration shows that Mira perceives her learning experience to be different in field-based contexts as opposed to campus-based contexts. The statement "it's a lot more easy to get 'in' and to remember" is an abstract statement and indicates that Mira has some difficulty articulating what constitutes the perceived difference. However, Mira's iterations about seeing what is "actually" happening implies that previous knowing about realities, or ontologies, might be insufficient or perhaps imprecise.

It seems that the students engaged with their surroundings in a manner that led them to nuance and develop their understanding of science education. The students made several remarks about the role of scientific method in biology. For instance, when asked about the value of field excursions in biology education, one student mentioned: "The fear is that biology might drown into laboratory work. Because there is [...] clearly a notion going towards much more laboratory work, 
much more microbiology and molecular biology." These are sentiments about epistemologies, in which, on the one hand, field-based activity facilitates situated knowing, while on the other hand, reductionist approaches, represented (perhaps unfairly) by microbiology and molecular biology, employ fieldbased skills and knowing to a lesser degree.

These conceptions of research method also underpin new conceptions of biological phenomena, with field experiences inducing an adjustment and further development of knowing. In particular, students previously understood that predators maim, kill, and eat their prey, but knowing about these phenomena progresses subsequent to engaging with such events.

One student mentioned how nature documentaries display animals killing each other. However, watching this occur in the field excursion was perceived as different and novel. When the students explained these experiences, they emphasized the uncertainty of the occurrences. Death could or could not occur, without human authorization or intervention. Thus, the students' conceptual understanding of death as ceasing to live had not changed, though this knowing seems to have generated increased connotations about the pain, sounds, and other inarticulate aspects of a predator eating its prey. Beyond any individual organism dying, comes the role death plays in biological systems and in evolution, that is, how a change in adaption can mean survival or becoming food for predators. A fate that can occur at any point:

Grant: Also in a sort of heartless way. Like this made me realize that you can't be like, "oh I want it to survive because it's cute" cause everything needs to feed. Like, it's not like you need to keep everything cute alive cause, then all the stuff that eats it dies [laughs].

Kim: Or a cute little thing kills all the other cute little things.

The above statements from two students indicate their field experiences with death. The indication is that cuteness is not a basis for survival. This is a further revelation about the natural world being subject to enormous pressures at several points, all of which fuel evolution. Thus, the students gain access to a profound body of knowing that advances their thinking about biological systems.

\section{Keeping Guns Loaded: Apprenticeship}

The third analytic unit of Rogoff's (1995) three-pronged understanding of sociocultural activity is apprenticeship. "Apprenticeship" is a term perhaps most commonly associated with work and working communities. Lave and Wenger's (1991) notion of legitimate peripheral participation and situated learning was developed as a variant of the apprentice metaphor. Lave and Wenger and Rogoff are careful to distinguish their theorizing of apprenticeship from a master/novice conception. They emphasize that different members of a working community contribute with different capacities, so that an individual's development in an apprentice process is not simply linear, but dynamic. One can imagine that, in a fieldwork community, there are students with specific expertise who contribute in other students' activities and teachers with varied interests and capacities who engage and contribute with varied levels of intensity.

Rogoff (1995) warns that the apprenticeship aspect of academic life is difficult to analyze, given that researchers themselves are embedded inside this culture. She defines apprentice- ship as the following: "it focuses on a system of interpersonal involvements and arrangements in which people engage in culturally organized activity in which apprentices become more responsible participants" (1995, p. 143). This conception of apprenticeship thus closely resembles Lave and Wenger's notion, in which apprenticeship learning is understood as increased levels of participation. These increased levels of participation pertain to individuals' ability to undertake and change practices within the community that they are engaging in (Gherardi, 2009). It is therefore worth noticing that students emphasized epistemology and research method in general during their interviews. Their tutoring of one another during the sampling with wooden frames and their increased levels of autonomous research work may be construed as part of an apprenticeship process. This seems to strengthen Rogoff's (1995) argument that apprenticeship, guided participation, and participatory appropriation are processes, wherein one process cannot be fully comprehended without also examining the other two. Here, another contribution is the teachers' facilitation of methods, vocabulary, and dispositions (i.e., appropriate values to bring to working with biology) to the students' experience. An example of the communal aspect of the field excursion, that which Rogoff has termed apprenticeship, is given here:

The teachers decided several of the stops on the cruise, one of which was the walrus beach, this is a location where walruses remain over long periods of time to find food, breed, and where polar bears attempt to attack and eat them. The location's most striking feature was the permeating smell: It was putrid and sweet, and mixed with the salty smell of the ocean to create a smell I have never smelled before. The teachers smiled, and told us about the origin of the smell: the walruses' feces. There were no walruses there at this time of year, though the teachers, in addition to the mirth about the smell, were quick to organize students because the presence of walrus smell also served to attract polar bears. One student with a gun had to be positioned at the start and another at the end of the column of students as we moved around the area.

The students were all trained to handle guns before being allowed on the cruise, to guard against polar bears. In the above excerpt, the teachers act both as facilitators for access to novel areas with interesting characteristics and as models for the proper way to behave: in some areas, polar bears can be more prevalent than in others. This was one such area. Working in an Arctic environment requires this sort of presence of mind and repeated assessments about potential dangers from both wildlife and weather. In some instances, weather and polar bear danger can interact, as low visibility (e.g., caused by fog or snowdrifts) can make for a very short warning interval before a polar bear appears.

The following excerpt displays a group's exposition about the development from the planning phase on campus to how the field excursion turned out. Two students were concerned about the sampling process, while Mira seemed less concerned about the convoluted nature of sampling, as she had performed the procedure previously. This displays the dynamic relationships among the students; different students found themselves to have specific capacities and experiences beneficial to the group as they engaged with their work. The students took the initiative at different turns; as the following extract illustrates, 
no one student assumed a permanent leadership position. Thus, the students' experiences show a dynamic apprenticeship as advanced by Rogoff (1995), wherein one student exhibits familiarity with a specific setting (i.e., a field excursion). As suggested by Fuller et al. (2005), participation in work is not a finite process, in which individuals develop in order to fully participate and then stop. Rather, all members of a practice undergo development and change as they progress in their work. Thus, while Mira conveyed familiarity with conducting fieldwork, she certainly stood to learn, as she would engage in fieldwork in the high Arctic for the first time.

Mira: I mean I have experience with fieldwork; I did it like three times. So I kind of [saw] that everything will be easy in the field because I know how fieldwork can work out, we just think about, "oh I want to test out this factor and this factor" and then you, it doesn't come out the way you want it to be, so I think that was really good [...]

Paula: I think like in the beginning it took some time to actually get to know how, what actually, what to do, but once that was done it was quite alright.

Lea: and then also be able to take things as they come on the cruise in the field.

Mira: Yeah, yeah, definitely.

Lea: Like to be able to collaborate about making a new decision. "Okay we need to do it in another way," "we could do it like this," "okay that will work."

\section{DISCUSSION}

\section{Students Participating/Working as Scientists}

The aim of this paper was to examine how students' work in a specific field excursion pertained to their learning of biology; this aim was formulated in the following research question: How does the students' engagement with fieldwork practices influence their development of biological knowing? Learning was examined as a sociocultural activity, that is, how it emerged through situated, participatory processes. This approach was argued to be appropriate, because field excursions by definition center around the movement of students into new circumstances in which they can engage in biological practices, circumstances that encompass both the physical environment (i.e., the walrus beach or bird cliffs) and interactions with other members of the field excursion (i.e., students and teachers).

This three-part analysis has put emphasis on how individuals (i.e., participatory appropriation), participation processes (i.e., guided participation), and institutions/community (i.e., apprenticeship) interact to create learning circumstances. All of these aspects are present in the students' experiences, meaning that an investigation of the students' learning in a field excursion should examine all three aspects of the students' experience to capture important learning activities. In her conceptualization of the tree dimensions, Rogoff (1995) put emphasis on the individual dimension, participatory appropriation, as this was a more novel sociocultural concept. In the present study, the students' discussion of their dispositions (i.e., values toward working with and utilizing specific sets of knowledge), their development of their scientific understanding, and their participation through working in a science project were particularly salient aspects of their expe- rience. Therefore, in correspondence to Rogoff's (1995) emphasis on participatory appropriation, the present study discusses these personal aspects of the sociocultural activity in the field excursion. This manifests as personal knowing, in which individuals advance their knowing as they enact biology; they sense, they work, and they engage the convoluted realities of practice.

According to Polanyi (1962), the assessment of a performance is a constant source of contention, particularly among those proficient in a particular discipline, whom one would think had a well-defined parameter by which to determine excellence. In terms of biological knowing, the quality of data collection is determined by some more or less transparent measures, such as statistical robustness of the research design and cohesiveness to established theoretical concepts. Method literature in biology (as in other disciplines) consistently underlines the importance of disseminating these factors (see, for instance, Sokal and Rohlf, 1995). In contrast, as shown by the students' experiences, the quality of the data collection is determined by several situated practices: for example, choice of study design, organisms, and sites most appropriate for attaining the research aims. As experienced by the students as they attempted to conduct research, a biologist, like many other empirical researchers, also benefits from assessing the circumstances surrounding the context of the sample, that is, location, weather, and common cohabiting species. These are appraisals that are performed through developing diverse dimensions of knowing, not least tacit knowing. In addition, subsequent to data collection, knowing about and familiarity with these circumstances may help biologists interpret results. All of these points were salient in the students' accounts and in the observation of the students' activities. Their initial planning was altered as they came to grips with the materials they were supposed to investigate.

The students' interpretations of the available materials were developed in a process in which their experiences were construed through participation; an agreed-upon procedure was established, consistently challenged, and re-established. This was particularly clear in their work on sampling plots, wherein basic concepts such as what constitutes a stone versus sand were subject to change. The students' engagement with these challenges indicate that repeated discussions led them to appraise their own knowing, in particular concerning concepts they had engaged during course work such as properties of Arctic flora and bird cliffs. This knowing developed as the concepts were challenged and understood in the context of the field-based community, that is, a relationship evolved between sociocultural activity and conceptual learning (Kelly and Green, 1998).

In some aspects, the students' experiences seem to reflect Schön's (1987) proposed dichotomy between professionals' lucid planning of activity on the one hand and the more convoluted enactment of the activity on the other. In Schön's (1987) conception of learning, education is merely an ad hoc preparation for actual activity, which is only learned in situ, that is, through work. Increased learning is attained in direct confrontation and repeated interaction with the convoluted realities of practice. On this basis, it seems clear that a comprehensive characterization of biology learning in the field must include an analysis of tacit knowing. Here, it is also worth noticing that the students' experiences are also characterized by sensory experiences. This is in line with sociocultural theory, in which the material world plays a decisive role in activity (and in learning). 
Smell, which was so important on the walrus beach, is one such example and is perhaps underappreciated in discussions of situated learning (see, e.g., Low, 2005).

In sum, the students' emergent knowing was constituted by experiences that were formed and developed through working with various practices and reflected upon individually and in concert with peers, teachers, and other coparticipants (Lave, 1997). As the students' narratives show, the students construed several of their experiences in relation to other phenomena with larger consequences. For instance, one student argued that natural sciences should include more than laboratory work, while others emphasized their emotional reaction to observing the real-time consequences of how killing and eating are parts of natural systems.

\section{Teachers and Students Participating in a Joint Practice}

Given that the field excursion examined here showed several important learning processes, some ramifications for teaching and learning will be discussed. Particularly, practice-oriented theories of learning have been criticized as inadequate in their efforts to examine education settings (e.g., Lave and Wenger, 1991), due to the difference between teacher and student practice (i.e., the teacher teaches, the students study the curriculum). Following this discussion, a sociocultural conceptualization of field-based learning is suggested (see Table 2).

The analysis suggests that the students pursue knowing on the basis of their individual dispositions rather than via a predetermined process; new knowing is approached based on prior personal experiences to make sense of the reality that students immediately construe (Polanyi, 1962). Thus, biology teachers can exploit field excursions to aid students' conceptual learning in this regard. Students are afforded with access to circumstances that are novel; they are also given access to and participate in genuine biology work. The students then negotiate their participation in these practices, based on their subjectivity and their exhilaration in the commencement of the work.

Teachers often describe their teaching as an activity separate from the students' activity of learning (Sunal et al., 2001). In the case of field excursions, students and teachers are coparticipants in a joint activity, even though their roles are formally different. Teachers are more or less responsible for the facilitation and organization of fieldwork-related activities, and students are (expected to be) focused on carrying out whatever fieldwork activities the teacher has planned. However, during the enactment of the fieldwork, students and teachers coparticipate at several instances; they discover new materials, they investigate them, they observe phenomena, and they discuss the work's significance. As Rogoff (1995) observes in her discussion on apprenticeship, new members to the active working community can engage dynamically. This means that teachers and students can aid one another's progress in science, though teachers certainly influence many of the activities (and therefore the learning) that takes place in a field excursion. Billett (2004) has proposed that participation is a salient metaphor to understand learning in work, because it necessitates examining both the way in which individuals work together and the foundation from which the individuals decide to engage in participation (i.e., their dispositions).

It is important here to interject that the participatory practice that manifests itself in a fieldwork setting is not strictly confined to the field. The participatory process arose on campus as students planned and developed their projects. Overall, the students' formation and identification of themselves as biologists derives from their construing of biology-related practices across their project-based work. Hence, fieldwork as a tacit learning process is not strictly a process that occurs by chance during noncampus activities. For instance, the students were active participants in their group research projects and became observers when teachers selected sites and led students to locales of which they had no previous knowledge.

Cox (2005) suggests that advances in organizational learning in modern institutions are characterized by increasingly detailed learning outcome descriptions and assessment. Indeed, the practices that arise in prolonged curricular activity are both steered by a teacher and planned according to learning outcomes. Field excursions certainly carry an element of both, but also provide engagement with practices more dependent on a joint enactment of language, tools, and other activities that constitute working in the field of biology.

The students' work in the field excursion represents an activity that aids personal integration of diverse expressions of knowing into a more cohesive conceptualization of biological science. This was achieved by the sampling and investigation of phenomena (death, bird cliffs, or the smell of walruses) as they occurred in the field. This development is similar to Knorr Cetina's (1999) accounts of knowing in scientific communities, where different cultures within disciplines build and develop scientific knowing and scientific methods through complex procedural and participatory practices to which the members of different sciences adhere. To enact these activities themselves, students must experience and mediate through interaction with peers, teachers, and others (Mascolo, 2009).

Brown and Duguid (1991) hold that learning in working practices is a function of tacit knowing as much as curricular or

TABLE 2. Sociocultural learning in field excursions

\begin{tabular}{|c|c|}
\hline Expression & Associated knowing \\
\hline Participatory appropriation & $\begin{array}{l}\text { Advancing conceptions through observations and experiences } \\
\text { Discerning how particular observations, (i.e., a bird of prey killing another bird) are parts of a greater phenomenon } \\
\quad \text { (i.e., natural selection) } \\
\text { Expressing how their capacity to work in the field is relevant to enact science. }\end{array}$ \\
\hline Guided participation & $\begin{array}{l}\text { Coming to grips with common methods and approaches (i.e., practices) prevalent in a particular field, in this case } \\
\text { biology } \\
\text { Activity was directed in concert, to participate in biological fieldwork with associated knowing. }\end{array}$ \\
\hline Apprenticeship & $\begin{array}{l}\text { Self-identity as biologists, enacting biological practices in concert with teachers and fellow students } \\
\text { Through extended interaction with teachers and peers, students increased their participation with practices. }\end{array}$ \\
\hline
\end{tabular}


articulated activity. Thus, it is significant that the findings presented here encompass diverse sets of knowing; these engagements are pronounced in field excursions, as students work comprehensively on practical tasks, research methods, and ways of thinking about biology-for instance, their observation of bird cliffs and autonomous enactment of a short-term research project. A field excursion is a learning activity, wherein the students have agency and an opportunity to construe their actions into a larger context, that is, their biological knowing for instance, how sampling can translate into increased knowledge about the surrounding areas and the ecology present there. However, field excursions can also take the form of passive observation (Kent et al., 1997). Such field excursions can be defined as classroom lectures taking place outdoors. This emphasizes the need to include students as participants who can enact practices themselves in field excursions, something that is difficult to do if the students are afforded no agency. Given this caveat, the identified sociocultural processes with associated expressions of knowing are summarized in Table 2.

\section{CONCLUSION}

Students were afforded access to extraordinary circumstances by being able to travel, work, and learn in high Arctic conditions. This certainly affected the development of knowing, but practices found in a specific case may not be immediately transferable to all university institutions with regular funding. The strength of short-term ethnographic research is the emphasis on documenting and further developing in-depth data points, with the aim of advancing theory development and, in this instance, biology teachers' thinking when they undertake field excursions.

With respect to the research question "How does the students' engagement with fieldwork practices influence their development of biological knowing?," the investigation shows that field excursion experiences can have an important impact on individuals' trajectories as cultivators of disciplinary knowing and can affect students' thinking about subsequent investigations, projects, and work. Through sociocultural analysis, various learning activities were discerned, and it is apparent that various aspects of situated knowing were prevalent in the students' experiences.

Further studies must be performed to determine the transfer of this knowing to different circumstances, though the post-field excursion interviews seems to point to dispositional and conceptual advances in the students' learning, especially in terms of stances toward epistemology and the role of fieldwork in science in general and biology in particular. To provide these affordances, students must enact science themselves. They must work and through their own agency construe their own role as biologists who contribute to new knowledge about the natural world.

\section{ACKNOWLEDGMENTS}

Thanks to Pernille B. Eidesen, Øystein Varpe, Kath Dickinson, and Tina Dahl for access and early feedback on the interview guide. Thanks to Hanne Riese, Gaute Velle, Arild Raaheim, and Stephen Billett for valuable feedback on the article and design. A special thanks to all student participants. The research project was funded by the Norwegian Research Council (NFR) through the project PRIME and by the Norwegian Agency for Quality Assurance in Education (NOKUT) through the Centre for Excellence in Biology Education (bioCEED).

\section{REFERENCES}

Angrosino, M. V. (2005). Recontextualizing observation: Ethnography, pedagogy, and the prospects for a progressive political agenda. In Denzin N. K., \& Lincoln, Y. S. (Eds.), The SAGE handbook of qualitative research (pp. 729-745). Thousand Oaks, CA: Sage.

Billett, S. (2004). Workplace participatory practices. Journal of Workplace Learning, 16(6), 312-324. https://doi.org/10.1108/13665620410550295

Billett, S. (2007). Including the missing subject: Placing the personal within the community. In Hughes, J., Jewson, N., \& Unwin, L. (Eds.), Communities of practice: Critical perspectives (pp. 55-67). London: Routledge.

Boyle, A., Maguire, S., Martin, A., Milsom, C., Nash, R., Rawlinson, S., .. Conchie, S. (2007). Fieldwork is good: The student perception and the affective domain. Journal of Geography in Higher Education, 31(2), 299317. https://doi.org/10.1080/03098260601063628

Brown, J. S., \& Duguid, P. (1991). Organizational learning and communities-of-practice: Toward a unified view of working, learning, and innovation. Organization Science, 2(1), 40-57. http://doi.org/10.1287/orsc 2.1.40

Cox, A. (2005). What are communities of practice? A comparative review of four seminal works. Journal of Information Science, 31(6), 527-540. http://doi.org/10.1177/0165551505057016

Creswell, J. W., \& Miller, D. (2000). Determining validity in qualitative inquiry. Theory into Practice, 39(3), 124-130.

Duguid, P. (2005). "The art of knowing": Social and tacit dimensions of knowledge and the limits of the community of practice. Information Society, 21(2), 109-118. https://doi.org/10.1080/01972240590925311

Fuller, A., Hodkinson, H., Hodkinson, P., \& Unwin, L. (2005). Learning as peripheral participation in communities of practice: A reassessment of key concepts in workplace learning. British Educational Research Journal, 31(1), 49-68. https://doi.org/10.1080/0141192052000310029

Gherardi, S. (2009). Community of practice or practices of a community? In Armstrong, S. J., \& Fukami, C. V. (Eds.), The SAGE handbook of management learning, education, and development (pp. 514-530). Los Angeles: Sage.

Gherardi, S. (2012). How to conduct a practice-based study: Problems and methods. Cheltenham, UK: Elgar.

Goulder, R., Scott, G. W., \& Scott, L. J. (2013). Students' perception of biology fieldwork: The example of students undertaking a preliminary year at a UK university. International Journal of Science Education, 35(8), 13851406. https://doi.org/10.1080/09500693.2012.708796

Hammersley, M., \& Atkinson, P. (2007). Ethnography: Principles in practice. London: Routledge.

Harland, T., Spronken-Smith, R. A., Dickinson, K. J. M., \& Pickering, N. (2006) Out of the ordinary: Recapturing the liberal traditions of a university education through field courses. Teaching in Higher Education, 11(1), 93106. https://doi.org/10.1080/13562510500400222

Hodges, D. C. (1998). Participation as dis-identification with/in a community of practice. Mind, Culture, and Activity, 5(4), 272-290. https://doi.org/ https://doi.org/10.1207/s15327884mca0504_3

Kelly, G., \& Green, J. (1998). The social nature of knowing: Toward a sociocultural perspective on conceptual change and knowledge construction. In Guzzetti, B., \& Hynd, C. (Eds.), Perspectives on conceptual change (pp. 145-182). New York: Routledge.

Kennedy, M., Billett, S., Gherardi, S., Grealish, L., Harteis, C., \& Gruber, H. (2015). Practice-based learning in higher education: Jostling cultures. In Kennedy, M., Billett, S., Gherardi, S., \& Grealish, L. (Eds.), Practice-based learning in higher education-Jostling cultures, Professional and Practice-based Learning (vol. 10, pp. 1-13). Dordrecht, Netherlands: Springer. https://doi org/10.1007/978-94-017-9502-9

Kent, M., Gilbertson, D. D., \& Hunt, C. O. (1997). Fieldwork in geography teaching: A critical review of the literature and approaches. Journal of Geography in Higher Education, 21(3), 313-332. https://doi.org/ 10.1080/03098269708725439

King, D., \& Ginns, I. (2015). Implementing a context-based environmental science unit in the middle years: Teaching and learning at the creek. Teaching Science, 61(3), 26-36.

Knorr Cetina, K. (1999). Epistemic cultures: How the sciences make knowledge. Cambridge, MA: Harvard University Press.

Latour, B. (1987). Science in action-How to follow scientists and engineers through society. Cambridge, MA: Harvard University Press. 
Lave, J. (1988). Cognition in practice. Cambridge, UK: Cambridge University Press. https://doi.org/10.1017/CBO9780511609268

Lave, J. (1996). The practice of learning. In Chaiklin, S., \& Lave, J. (Eds.), Understanding practice-Perspectives on activity and context (pp. 3-32). Cambridge, UK: Cambridge University Press.

Lave, J. (1997). The culture of acquisition and the practice of understanding In Kirshner, D., \& Whitson, J. A. (Eds.), Situated cognition: Social, semiotic, and psychological perspectives (pp. 63-82). Mahwah, NJ: Erlbaum.

Lave, J., \& Wenger, E. (1991). Situated learning: Legitimate peripheral participation. Cambridge, UK: Cambridge University Press.

Low, K. E. Y. (2005). Ruminations on smell as a sociocultural phenomenon. Current Sociology, 53(3), 397-417. https://doi.org/10.1177/ 0011392105051333

Marton, F., \& Säljö, R. (2005). Approaches to learning. In Entwistle, N. (Ed.), The experience of learning: Implications for teaching and studying in higher education (3rd ed., pp. 39-58). Edinburgh: University of Edinburgh

Mascolo, M. F. (2009). Beyond student-centered and teacher-centered pedagogy: Teaching and learning as guided participation. Pedagogy and the Human Sciences, 1(1), 3-27.

Mason, L. (2007). Introduction: Bridging the cognitive and sociocultural approaches in research on conceptual change: Is it feasible. Educational Psychologist, 42(1), 1-7. https://doi.org/10.1080/00461520709336914

Nicolini, D. (2012). Practice theory, work, and organization: An introduction (1st ed.). Oxford, UK: Oxford University Press.

Pink, S., \& Morgan, J. (2013). Short-term ethnography: Intense routes to knowing. Symbolic Interaction, 36(3), 351-361. https://doi.org/10.1002/ symb.66

Polanyi, M. (1962). Personal knowledge. Chicago: University of Chicago Press. Polanyi, M. (1966). The tacit dimension. Chicago: University of Chicago Press.

Rennie, L. J., \& Johnston, D. J. (2004). The nature of learning and its implications for research on learning from museums. Science Education, 88(S1), S4-S16. https://doi.org/10.1002/sce.20017

Rogoff, B. (1995). Observing sociocultural activity on three planes: Participatory appropriation, guided participation, and apprenticeship. In Wertsch, J. V., Del Río, P., \& Alvarez, A. (Eds.), Sociocultural studies of mind (pp. 139-164). Los Angeles: Cambridge University Press.
Roth, W.-M. (2005). Making classifications (at) work: Ordering practices in science. Social Studies of Science, 35(4), 581-621. https://doi.org/ 10.2307/25046660

Roth, W.-M., \& Bowen, G. M. (1999). Digitizing lizards: The topology of "vision" in ecological fieldwork. Social Studies of Science, 29(5), 719-764. https://doi.org/10.1177/1476127005050030

Roth, W.-M., \& Lee, S. (2004). Science education as/for participation in the community. Science Education, 88(2), 263-291. https://doi.org/10.1002/ sce. 10113

Schön, D. A. (1987). Educating the reflective practitioner. San Francisco: Jossey-Bass.

Sfard, A. (1998). On two metaphors for learning and the dangers of choosing just one. Educational Researcher, 27(2), 4-13. https://doi.org/10.3102/0 013189x027002004

Silverman, D. (2011). Interpreting qualitative data (4th ed.). London: Sage.

Silverman, D. (2013). Doing qualitative research (4th ed.). Los Angeles: Sage.

Singer, S. R., Nielsen, N. R., \& Schweingruber, H. A. (2013). Biology education research: Lessons and future directions. CBE-Life Sciences Education, 12(2), 129-132. http://doi.org/10.1187/cbe.13-03-0058

Sokal, R. R., \& Rohlf, F. J. (1995). Biometry:. The principles and practice of statistics in biological research. New York: Freeman.

Strati, A. (2003). Knowing in practice: Aesthetic understanding and tacit knowledge. In Nicolini, D., Gherardi, S., \& Yanow, D. (Eds.), Knowing in organizations. A practice-based approach (pp. 53-75). Armonk, NY: M.E. Sharpe.

Sunal, D. W., Hodges, J., Sunal, C. S., Whitaker, K. W., Freeman, L. M., Edwards, L., ... Odell, M. (2001). Teaching science in higher education: Faculty professional development and barriers to change. School Science and Mathematics, 101(5), 246-257. https://doi.org/10.1111/j.1949-8594.2001 .tb18027.x

The Svalbard Science Forum, (n.d.). Research in Svalbard. Retrieved June 7, 2017, from www.researchinsvalbard.no/

Watson, T. J. (2012). Making organisational ethnography. Journal of Organizational Ethnography, 1(1), 15-22. https://doi.org/10.1108/20466741211220615

Wertsch, J. V. (1991). Voices of the mind. Cambridge, MA: Harvard University Press. 